\title{
Cervical Reconstruction after Cervical Myomectomy or Hysterectomy: Operative Challenges in Huge Cervical Fibroids
}

\author{
Monika Anant ${ }^{1}$, Shweta Gupta ${ }^{2}$
}

\begin{abstract}
Fibroids are an extremely common benign neoplasm of uterine smooth muscle but fibroids originating in cervix are uncommon ( $1 \%$ of all fibroids). Huge cervical fibroids pose operative challenge in both hysterectomy and myomectomy. We report two cases with a 24-week-sized central cervical fibroid with uterus sitting atop, i.e., lantern on the St. Paul's Cathedral appearance. The younger patient desirous of future childbearing underwent open cervical myomectomy followed by uterine cervix reconstruction and the postmenopausal women underwent hysterectomy. Keywords: Cervical fibroid, Cervical reconstruction, Hysterectomy, Myomectomy. Journal of South Asian Federation of Obstetrics and Gynaecology (2020): 10.5005/jp-journals-10006-1799
\end{abstract}

\section{INTRODUCTION}

Uterine leiomyoma are an extremely common benign neoplasm of uterine smooth muscle. Forty to sixty years age group can have symptomatic fibroid in more than $30 \%$ of women. ${ }^{1}$ By ultrasound screening, almost $51 \%$ of premenopausal women will be diagnosed with fibroids; however, they are rarer in premenarchal and postmenopausal women. Fibroids are the most common cause of hysterectomy in women too, about $30 \% .^{2}$

The incidence of cervical fibroids is much lower at $1-2 \%$ of total fibroids. ${ }^{3}$ They arise from infravaginal or supravaginal part of cervix, infravaginal cervical fibroids present as polyps, and supravaginal ones can be either an interstitial, subserous, or submucous fibroid. Depending on the position, they are anterior, posterior, lateral, or central. Huge central fibroids give the classically described appearance of "Lantern on St. Paul's Cathedral". The size can also vary from a few millimeters to several centimeters. Giant cervical fibroids are considered when it exceeds a size of $9 \mathrm{~cm}$ or a weight of $800 \mathrm{~g}$ as described by Pedraza et al. ${ }^{4}$

We present two cases of a 24-week-sized cervical fibroids (specimen weight 2,200 and 1,500 g), one in postmenopausal woman where diagnosis was confused with ovarian pathology and another in a young primipara. There is very less scientific evidence of conservative treatment (myomectomy) of giant cervical fibroids and their outcome.

\section{Case Descriptions}

\section{Case 1}

A 24-year-old married P1L1 woman presented AlIMS-Patna outpatient department with complain of heavy menstrual bleeding for 3 months after a period of lactational amenorrhea 9 months and heaviness in lower abdomen since 2 months. Her child's birth was only 1 year ago by a cesarean section where no fibroid was mentioned in operative notes. General and systemic examination were normal except mild pallor. Per abdominal examination revealed 28 weeks firm, regular, nontender, central suprapubic mass with restricted mobility (Fig. 1). Per speculum examination showed cervix to be smooth and healthy but short. On per vaginal
1,2Department of Obstetrics and Gynaecology, All India Institute of Medical Sciences, Patna, Bihar, India

Corresponding Author: Monika Anant, Department of Obstetrics and Gynaecology, All India Institute of Medical Sciences, Patna, Bihar, India, Phone: +91 7764946249, e-mail: drmonika.anant@gmail.com

How to cite this article: Anant M, Gupta S. Cervical Reconstruction after Cervical Myomectomy or Hysterectomy: Operative Challenges in Huge Cervical Fibroids. J South Asian Feder Obst Gynae 2020;12(4): 254-257.

Source of support: Nil

Conflict of interest: None

examination, a $20 \times 20 \mathrm{~cm}$ firm, regular abdominopelvic mass with restricted mobility was palpated, the uterus was not felt separately but cervix seemed to be attached with mass. All vaginal fornices and pouch of Douglas (POD) were full of mass.

On ultrasonography (USG), a large hypoechoic mass $(20 \times 18 \mathrm{~cm})$ arising from pelvic cavity and extending above umbilicus was noted. Uterus and adnexa were not seen separately with mild

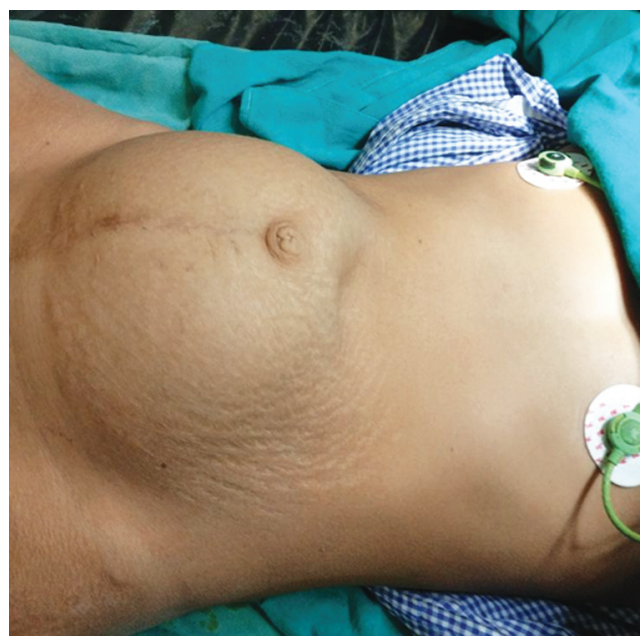

Fig. 1: Lower abdominal mass of 28 weeks size

(-) The Author(s). 2020 Open Access This article is distributed under the terms of the Creative Commons Attribution 4.0 International License (https://creativecommons. org/licenses/by-nc/4.0/), which permits unrestricted use, distribution, and non-commercial reproduction in any medium, provided you give appropriate credit to the original author(s) and the source, provide a link to the Creative Commons license, and indicate if changes were made. The Creative Commons Public Domain Dedication waiver (http://creativecommons.org/publicdomain/zero/1.0/) applies to the data made available in this article, unless otherwise stated. 
right-sided hydroureteronephrosis. Magnetic resonance imaging (MRI) was performed for fibroid mapping and a posterior cervical fibroid or pedunculated broad ligament fibroid $(18 \times 15 \times 10 \mathrm{~cm})$ with uterus pushed superiorly, anteriorly, and to right, with small POD collection was suggested.

Considering her young age and desire for future childbearing, she was planned for myomectomy. The size of the mass precluded any medical management offered to her to relieve her symptoms. On laparotomy, normal-sized uterus $(6 \times 4 \mathrm{~cm})$ was sitting on top of a huge globular mass like a lantern on the dome of St. Paul's Cathedral. Both tubes and ovaries were normal. Ureters were identified and were dissected out by opening the retroperitoneum to help visualization during the surgery and prevent its injury. A vertical incision on posterior aspect of cervix was performed and a single huge myoma excised out. Bleeding was controlled by hypotensive anesthesia and injection of diluted vasopressin into myoma bed prior to incision. There was a longitudinal split in the posterior cervical wall extending from isthmus until posterior lip of about $18 \mathrm{~cm}$ (Fig. 2). Since the uterine cavity was entered near isthmus, a Foley's catheter (8 Fr) was inserted with bulb inflated up to $3 \mathrm{~mL}$ in uterine cavity passing through now opened cervix into the vagina (Fig. 3). Cervical reconstruction was performed with multiple layers of muscular tissue of cervix brought to midline by sutures over the Foley's catheter. Reconstructed cervix measured $15 \mathrm{~cm}$ after repair. Myomectomy specimen weighed $1.5 \mathrm{~kg}$ (Fig. 4). Foley's catheter was kept for 1 week postoperatively. She was also put on low dose combined oral contraceptive pills for contraception. Patient was followed up monthly for first 3 months, then 3 monthly for 1 year. She is now having regular menstruation with no hematometra and her recent ultrasound (9 months postoperatively) shows cervical length of $4.8 \mathrm{~cm}$, normal caliber.

\section{Case 2}

A 56-year-old postmenopausal P2L2 woman presented with complaints of difficulty in micturition with decreased flow and lower abdominal pain for 10 days. There was no history of early satiety or distension and no episode of postmenopausal bleeding. She had menopause 5 years ago with previous normal cycles, with no significant past or family history.

General and systemic examination were unremarkable. Abdominal examination revealed a 24-week-sized abdominopelvic

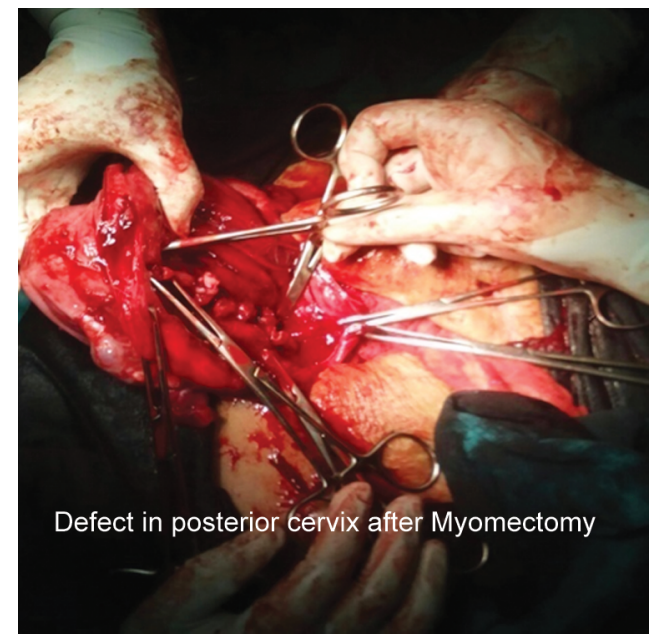

Fig. 2: Myomectomy performed, intact uterine posterior wall, $15 \mathrm{~cm}$ defect in posterior wall of cervix lump extending a little above umbilicus which was regular in contour, firm consistency, nontender with mobility sideways. Cervix was pulled up on vaginal fornix and all fornices were full of mass. On per vaginal examination revealed firm abdominopelvic mass of approximately $18 \times 16 \mathrm{~cm}$ size, with restricted mobility, cervix seemed to be attached and bilateral adnexa not palpable. USG revealed solid mass arising from pelvis ( $18 \times 15 \mathrm{~cm}$ size). Bilateral ovaries or uterus could not be seen separately. With provisional diagnosis of ovarian mass, markers were performed (normal Ca-125), she was planned for exploratory laparotomy. On laparotomy, it was found 10 weeks uterus sitting on the top of cervical fibroid $(18 \times 16 \mathrm{~cm})$ like lantern on the top of St. Paul's Cathedral (Fig. 5). Both tubes and ovaries were normal looking. No ascites was present. Cervical myomectomy was performed after identifying and dissecting bilateral ureters to ease out putting uterine artery clamps for completing total hysterectomy. Myomectomy specimen weighed 2,200 g (Fig. 6). A part of myoma bed behind posterior vaginal wall was closed with concentric sutures to close dead space and sutured with vault. There was a need for relaparotomy due to fresh blood through the pelvic drain and deteriorating vitals of the patient on 2 nd postoperative day. There was bleeding from the leftover myoma bed, which was resutured in multiple layers and bilateral internal iliac artery ligation was performed. Her further postoperative period was uneventful. In her follow-up visits, she is doing well.

\section{Discussion}

Giant gervical fibroids are encountered rather uncommonly by gynecologists. Cervical fibroids, unlike those in body of uterus, are usually single. Not much is known about the growth and progression of cervical fibroids and they rarely undergo malignant change $(<0.1 \%) .^{5}$

Cervical fibroid polyps are easily accessible as mass protruding from the cervix in the vagina ${ }^{6}$ and hence vaginal myomectomy can be performed by clamping, cutting, and ligating the stalk.

Central supravaginal fibroids expand the cervix equally in all directions in the pelvis and the uterus is displaced and elevated on top of the mass. The cervical fibroid causes pressure symptoms like frequency, urgency, retention of urine due to urethral obstruction, and hydroureteronephrosis due to ureteral obstruction. ${ }^{7}$

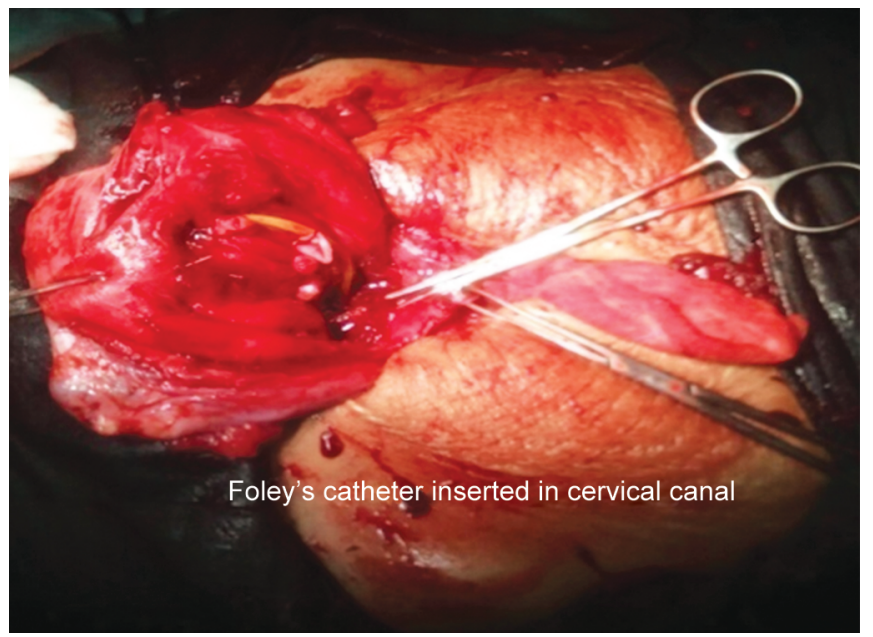

Fig. 3: Posterior wall of cervix repaired after inserting Foley's catheter to maintain continuity with uterine cavity 


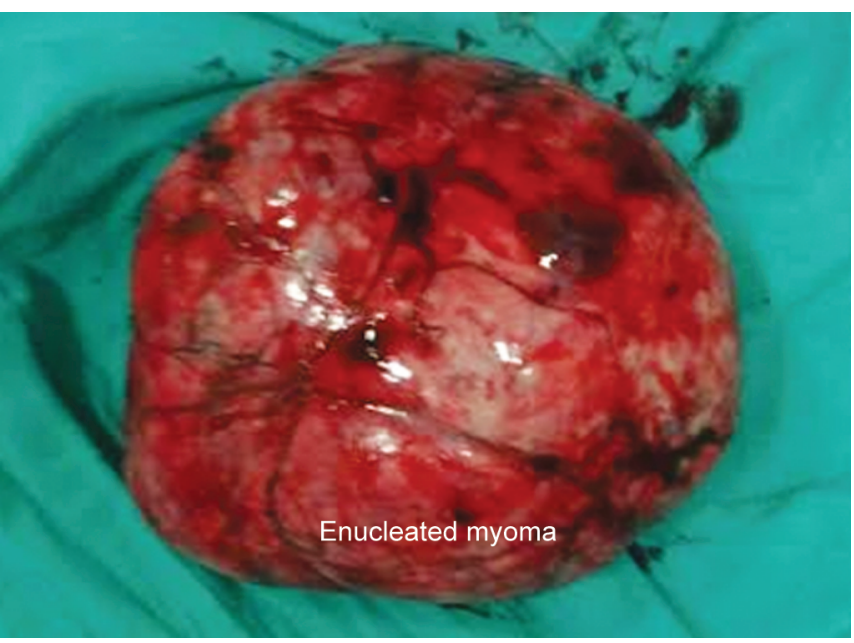

Fig. 4: Myoma specimen weighing $1.5 \mathrm{~kg}$

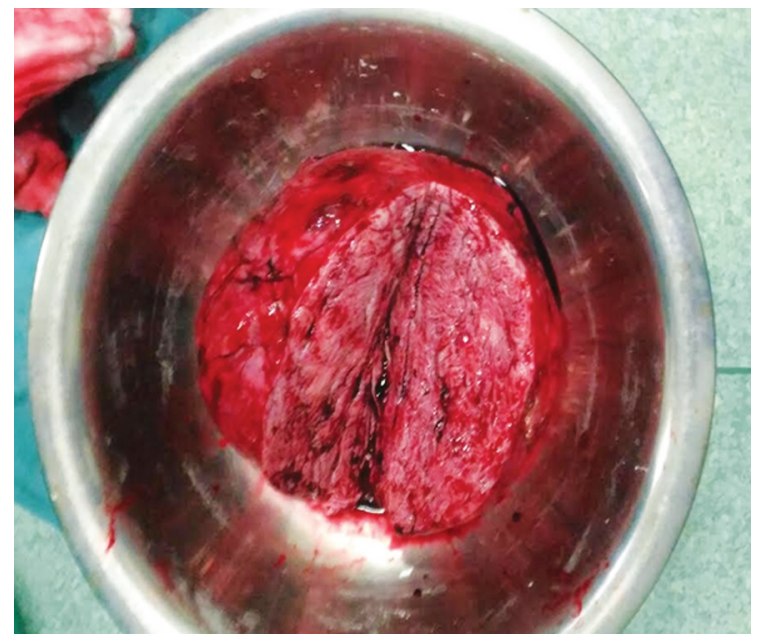

Fig. 6: Myoma specimen showing typical whorled appearance, weight $2.2 \mathrm{~kg}$

Dyspareunia and dysmenorrhea can also occur. The location of cervical fibroid in deep pelvis distorts the pelvic anatomy especially that of the urinary system, uterine vessels, and if attains larger sizes, can also get impacted in the pelvis.

Diagnosis is clinical by pelvic examination but imaging modalities like USG, hysterosalpingogram, hysteroscopy, and MRI help to detect number and positions of fibroids, give an idea about other associated pelvic pathology. ${ }^{8}$

For those having completed childbearing, hysterectomy is the procedure opted and myomectomy is performed for cervical fibroids where future childbearing is intended. For both operations, central cervical fibroids are surgically challenging as impacted fibroid leads to poor access to operative field in pelvis, increased blood loss due to difficult suturing of incisions, and altered anatomical relation of surrounding vital structures. ${ }^{9}$ Anatomical distortions due to cervical fibroids that need special care are location of uterine vessels, bladder peritoneal fold, and ureters. The safe route to prevent injury to any of these structures is to perform an enucleation/myomectomy followed by hysterectomy for cervical fibroids. This method gives proper exposure in operative field,

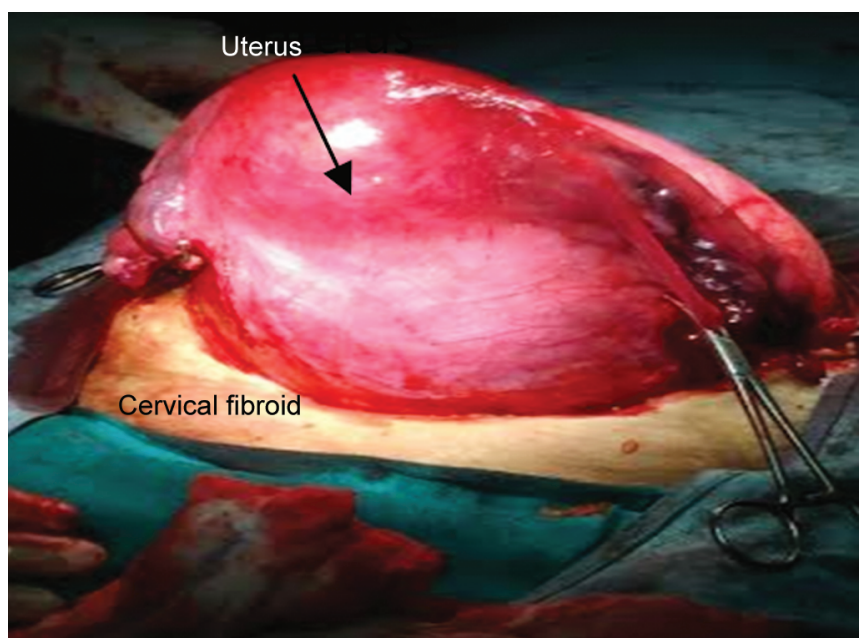

Fig. 5: Uterus on top of cervical fibroid

prevents inadvertent injury to the ureters, and eases the clamping of the uterine vessels.

For enucleation, the capsular incision can either be transverse or vertical. In both our cases, we performed a posterior vertical incision to enucleate the myoma and noted less blood loss and easier suturing. Hypotensive anesthesia, preoperative vaginal misoprostol, and infusion of diluted vasopressin in the myoma bed reduced intraoperative bleeding to a significant level.

Our hysterectomy patient had to undergo a repeat laparotomy for intraperitoneal hemorrhage on the second postoperative day in spite of careful closure of myoma bed. Hypotensive anesthesia intraoperatively may have led to non-recognition of myoma bed bleeder and postoperative cough in our patient might have dislodged a clot in a vessel in the myoma bed which led to intraperitoneal hemorrhage. Our experience emphasis that the importance of obliteration of dead space in myoma bed and perfect hemostasis.

Laparoscopic myomectomy for cervical myomas has been attempted and is safe in hands of laparoscopic experts. ${ }^{10,11}$

Uterine reconstruction is the norm after myomectomy but cervical reconstruction after cervical myomectomy is rarely performed. ${ }^{12}$ Removal of larger cervical fibroids causes larger defect in cervix and closure of defect may not give a patent endocervical canal to fulfil menstrual and childbearing functions. There was a $15-\mathrm{cm}$ defect in posterior cervix after myomectomy, which was successfully reconstructed and patient had a successful outcome in maintain regular menstrual cycles without dysmenorrhea or cervical obstruction.

\section{Conclusion}

Cervical fibroids pose surgical challenge for most surgeons. Medical management can be tried for smaller fibroids. For larger cervical fibroids, type of surgery (myomectomy/hysterectomy) should be decided on plans of future childbearing. Route of surgery vaginal, abdominal, or laparoscopic is determined by type (infravaginal or supravaginal fibroids) and the expertise of the surgeon.

Knowledge of the altered anatomical relationship of pelvic structures and meticulous hemostasis is the key for a complicationfree surgical outcome. Cervical reconstruction is a feasible option after cervical myomectomy even in huge cervical fibroids. 


\section{References}

1. Evans $P$, Brunsel $S$. Uterine fibroid tumors: diagnosis and treatment. Am Fam Physician 2007;75:1503-1508.

2. Myers ER, Barber MD, Gustilo-Ashby T, et al. Management of leiomyomata: what do we really know? Obstet Gynecol 2002;100(1): 8-17. DOI: 10.1097/00006250-200207000-00003.

3. Monaghan JM, Lopes T, Naik R. Myomectomy and the Management of Fibroids in Pregnancy, Bonney's Gynecological Surgery. 10th ed. pp. 87-943.

4. Pedraza S, Estepa Perez JL, Enteza MJF. Giant uterine fibromyoma. report of a case. Medisur 2013. 11.

5. Dicker RC, Greenspan JR, Strauss LT, et al. Complications of abdominal and vaginal hysterectomy among women of reproductive age in the United States. Am J Obstet Gynecol 1982;144(7):841-8484. DOI: 10.1016/0002-9378(82)90362-3.

6. Thompson JD, Warshaw JS, Hysterectomy Rock JA, et al. Telinde's Operative Gynecology. 8th ed., Philadelphia: Lippincott-Raven; 1997.
7. Mihmanli V, Cetinkaya N, Kilickaya A, et al. Giant cervical myoma associated with urinary incontinence and hydroureteronephrosis. Clin Exp Obstet Gynecol 2015;42(5):690-691.

8. Te Linde RW, Rock JA, Jones HW. Leiomyomata uteri and myomectomy, in TeLinde's textbook of operative gynecology. 9th ed., Philadelphia, PA: Lippincott Williams \& Wilkins; 2008

9. Monaghan JM, Lopes $A B$, Naik R. Total hysterectomy for cervical and broad ligament fibroids. In: Huxley R, Taylor S, Chandler K, ed. Bonney's gynaecologica surgery. 10th ed. Blackwell Publishing; 2004. pp. 74-86.

10. Chang WC, Chen SY, Huang SC, et al. Strategy of cervical myomectomy under laparoscopy. Fertil Steril 2010;94(7):2710-2715. DOI: 10.1016/j. fertnstert.2010.02.049.

11. Patel P, Munshi S, Banker M, et al. Handling cervical myomas.J Gynecol Endosc Surg 2011;2(1):30-32. DOI: 10.4103/0974-1216.85277.

12. Sharma S, Kaur EJ, Thakur R, et al. Myomectomy and cervical reconstruction in an unmarried girl with large cervical fibroid. JK Sci 2014;16(2):94-96. 